Arteterapia. Papeles de arteterapia y educación para inclusión social ISSN-e 1988-8309

http://dx.doi.org/10.5209/ARTE.60132

\title{
Hurgar en los miedos al cuerpo. La formación en artes de futuras maestras interpelando la obra de mujeres artistas
}

\author{
Ricard Huerta ${ }^{1}$
}

Recibido: 5 de mayo de 2018 /Aceptado: 22 de junio de 2018

Resumen. Planteamos el uso del arte contemporáneo en la formación de docentes. Consideramos de gran interés acercar los actuales dispositivos del arte a las futuras generaciones de maestros y maestras, ya que en el mundo del arte se están tratando temáticas sociales y culturales que van a resultar decisivas en la labor que deberán llevar a cabo quienes eduquen. Desde una perspectiva regeneradora y vitalista, proponemos una posibilidad de estrategias en la formación artística del colectivo docente. Integramos temáticas que habitualmente no se tratan en el ámbito escolar, pero que están vinculadas a las emociones, a las necesidades y a la vida cotidiana del alumnado. Conceptos como «el miedo» o «el cuerpo» permiten indagar en las problemáticas más cercanas, sin dejar de revisar lo que las artes han planteado al respecto desde siempre, ya que se trata de elementos con presencia constante tanto en nuestras vidas como en la historia del arte. Abordamos los conceptos utilizando la obra de las artistas Carmen Calvo y Anna Ruiz Sospedra. La metodología utilizada es mixta, combinando la Investigación Educativa Basada en las Artes con la «Artography». Entre los resultados obtenidos destacamos la gran aceptación por parte del alumnado universitario de los procesos innovadores utilizados.

Palabras clave: arte contemporáneo; educación artística; formación del profesorado; género; cuerpo.

\section{[en] Delving Into the Body Fears'. Teacher Training in Art Education Attending to the Work of Women Artists}

\begin{abstract}
We propose the use of contemporary art in training teachers. We want to bring the current devices of art to future generations of teachers, since in the art world they are dealing with social and cultural issues that will be decisive for future educators. From a regenerative and vital perspective, we propose a change of strategies in art education for teachers. We integrate topics that are usually not treated in Primary School environment, but are linked to the emotions, needs and daily life of students. Concepts such as «fear», or «body» allow us to investigate the problems, while continuing to review what the arts have put forward, as these are elements with a presence both in our lives and in the History of Art. We approach the concepts using the work of artists Carmen Calvo and Anna Ruiz Sospedra. The methodology is mixed, combining the Arts Based Educational Research with A/R/Tography. Among the results obtained we highlight the great acceptance by students of the innovative processes used.
\end{abstract}

Keywords: Contemporary Art; Art Education; Teacher Training; Gender; Body.

Sumario: 1. Plantear la educación artística de las futuras maestras desde el arte contemporáneo. 2. Partir del arte producido por mujeres para hablar de cuestiones como el miedo o el cuerpo. 3. Interpretaciones artísticas del miedo y del cuerpo por parte de las futuras maestras. 4. Mostrar las producciones del alumnado en los espacios de tránsito de la facultad. 5. Conclusiones. 6. Referencias.

1 Universitat de Valencia. Instituto de Creatividad e Innovaciones Educativas. Profesor del Departamento de Didáctica de la Expresión Musical, Plástica y Corporal

e-mail: ricard.huerta@uv.es 
Cómo citar: Huerta, R. (2018). Hurgar en los miedos al cuerpo. La formación en artes de futuras maestras interpelando la obra de mujeres artistas, en Arteterapia. Papeles de arteterapia y educación para inclusión social 13, 2018, 33-52.

A lo largo de treinta años de experiencia como profesor universitario implicado en la formación de maestros, he venido comprobando la eficacia del uso del arte contemporáneo en las clases que imparto. Hablar al alumnado de Magisterio sobre arte actual permite acercarles al mundo de la creación artística y la educación en artes desde una perspectiva muy cercana a sus intereses. Y si hablamos de arte actual, no podemos perder de vista la importancia que adquiere la presencia de mujeres artistas en el panorama internacional. Lo que propongo es reivindicar el papel de las mujeres en la creación artística, desarrollando en las aulas proyectos con temáticas atractivas e innovadoras, como puedan ser los conceptos «el miedo» o «el cuerpo». Se trata de aspectos que suelen ocupar los intereses de las creaciones realizadas por mujeres artistas, además de constituir elementos vitales para el alumnado. Esconder estas realidades, ocultar su relación con las construcciones culturales, supone enmascarar la posibilidad de analizar cuestiones tan vigentes como la violencia contra la mujeres o la presencia obstinada del patriarcado en nuestras relaciones sociales cotidianas.

\section{Plantear la educación artística de las futuras maestras desde el arte contemporáneo}

El arte está presente tanto en las galerías y museos como en las acciones que realizan artistas contemporáneos en el espacio urbano y en los entornos informales (Huerta y Alonso, 2017), muchas veces en colaboración con las comunidades. Las nuevas emergencias del arte nos permiten tratar cuestiones cercanas al alumnado, las mismas problemáticas que vibran en las creaciones contemporáneas. Además de acercarnos a sus intereses, el hecho de plantear temáticas próximas les ayuda a reflexionar sobre problemas que son actuales y que al mismo tiempo mantienen un recorrido histórico en tanto que cuestiones tratadas en todos los momentos de la historia. Algunos conceptos son constantes en el arte de nuestro tiempo y en el de cualquier época: la vida, la muerte, el amor, el odio, el poder, los derechos humanos, la educación, el cuerpo. Soy partidario de revisar lo que ha ocurrido en la historia del arte siempre a partir de lo que está pasando en la actualidad. Por ejemplo, si hablamos del cuerpo humano, o de la identidad, podríamos empezar con las fotografías de Cindy Sherman, y a partir de aquí recuperar otros artistas anteriores como Rembrandt, Caravaggio, Frida Kahlo, Ribera, Louise Bourgeois o Miguel Ángel. Esto es posible si se trabaja desde los llamados «motivos visuales», un concepto desarrollado por Jordi Balló (2000). El concepto de motivo visual nos ayuda a entender las imágenes en un sentido de trayectoria de la mirada. Gracias a los motivos visuales enlazamos con los intereses del alumnado, ya que de este modo pueden opinar, participar activamente e introducir ideas propias.

Nuestro alumnado está compuesto por futuros maestros, especialmente maestras, ya que la mayoría son mujeres (Huerta, 2012). Estamos hablando de futuras docentes, de profesionales que no se van a dedicar a la producción artística ni tampoco al comercio con obras de artistas. Esto significa que su participación en la creación artística está lejana al concepto mercado del arte, lo cual no impide que puedan convertir el arte en una herramienta capaz de generar grandes satisfacciones pedagógi- 
cas. Les animo constantemente a utilizar las posibilidades del arte como argumento educativo, como fuerza capaz de revolucionar la sociedad, como aliento que inspira los cambios y las mejoras sociales (Huerta, 2014).

También revisamos las ideas que transmiten las autoras Martins y Demarchi (2016) cuando recomiendan utilizar dispositivos que remitan al campo del arte para pensar la escuela: «diálogos en el terreno de las experiencias y de las posibles relaciones entre arte y educación» (Martins y Demarchi, 2016, p.129), al tiempo que defienden el arte participativo, como una tendencia que supone implicar a muchas personas, conectándolas en redes de mediación cultural. Siempre teniendo en cuenta la lección de Paulo Freire (2015), las tendencias actuales que recogen las autoras apuntan hacia la pedagogía crítica, donde se plantea una ruptura de la jerarquía entre profesorado y alumnado, así como una «valorización de la participación como ruta de empoderamiento, en correlación directa con la quiebra de la especificidad del lenguaje y prestando más atención a las posibilidades de actuación de los usuarios del arte» (Martins y Demarchi, 2016, p.132)

Son tantas y tan variadas las formas de representación que se dan en el actual panorama artístico que conviene orientar al alumnado hacia un determinado espectro de posibilidades. En mi caso intento que conozcan nuevas formas artísticas (performance, videodanza, instalaciones, acciones) en las que además de contar con las voces femeninas, se tenga en cuenta la participación ciudadana y la problemática de la precariedad (Zafra, 2017), urdiendo redes de compromisos personales y sociales (Laddaga, 2006).

\section{Partir del arte producido por mujeres para hablar de cuestiones como el miedo o el cuerpo}

En mi trabajo docente siempre he incorporado el arte hecho por mujeres, no solamente porque lo considero fundamental, sino también porque sigue existiendo una tendencia a no hacer visible esta realidad. Cuando hablamos de arte contemporáneo nos referimos al que se está realizando en la actualidad, y por tanto hablamos de artistas vivos, de personas a quienes incluso podemos conocer personalmente. $\mathrm{Si}$ estas personas son mujeres artistas, entonces estamos incorporando un rasgo de género que entronca con esta realidad y le confiere importancia. La mayoría de mi alumnado son mujeres. Creo que mis alumnas, las futuras maestras, deben conocer a estas artistas que crean y defienden sus propuestas en las galerías, en los museos y en los espacios comunitarios. Nuestra metodología activa se basa en los Proyectos de Trabajo. Con los grupos de la mención de «Artes y Humanidades» planteamos proyectos abiertos, con títulos que puedan resultar sugerentes como «identidades», «el miedo», «el cuerpo», «la ciudad», o «las narrativas personales». Cada proyecto se inicia revisando la obra de una artista, mujer, y viva. Algunas de estas artistas son Barbara Kruger, Chiharu Shiota, Gillian Wearing, Jenny Holzer, Rebeca Horn, Maribel Doménech, Ana Navarrete Carmen Calvo o Anna Ruiz Sospedra. Al conocer la obra de estas artistas pasamos a elaborar un discurso propio, tanto artístico como pedagógico. Cada grupo de clase elige el nombre de una artista e indaga en la realidad de dicha creadora. Es un modo de fomentar el conocimiento de estas artistas, y es el propio alumnado quien explica en clase por qué han elegido a la creadora con la que se sienten identificadas. 
Al utilizar los proyectos de trabajo todas las decisiones se van generando de forma colaborativa. Fernando Hernández prefiere la denominación Proyectos de Trabajo porque, según nos dice, aprender mediante proyectos de trabajo no es lo mismo que hacer proyectos. El autor plantea que el conocimiento que se requiere para dar sentido al mundo en el que se vive no está organizado por hechos, conceptos, procedimientos y valores fijos y dados, sino que es un proceso cambiante y en construcción. Afirma que «el conocimiento no se configura como una línea recta, sino que está hecho de historias y visiones sobre los fenómenos, refleja intereses que reafirman y que excluyen» (Hernández-Hernández, 2000, p. 82). Utilizar Proyectos de Trabajo supone acercarse a un tema o a un problema para tratar de desvelar sus enigmas, cuestiones y contradicciones, generando así una «conversación cultural», en la que se trata de dar sentido y transferirlo a otras situaciones. Dicha conversación sirve de puente entre las identidades de los aprendices, el entorno de aprendizaje y la conexión que se establece con lo que se aprende. Por eso «aprender es también una práctica emocional, no sólo una cuestión cognitiva y comportamental» (HernándezHernández, 2000, p. 80). Los proyectos de trabajo permiten desarrollar un discurso abierto que evoluciona con la participación e implicación de todo el alumnado y el profesorado. Al iniciar el proyecto sobre la temática «El miedo» explicamos la obra de Carmen Calvo, ya que se trata de una artista que imprime mucha tensión en sus piezas. Su trabajo resulta verdaderamente turbador (Figura 1).

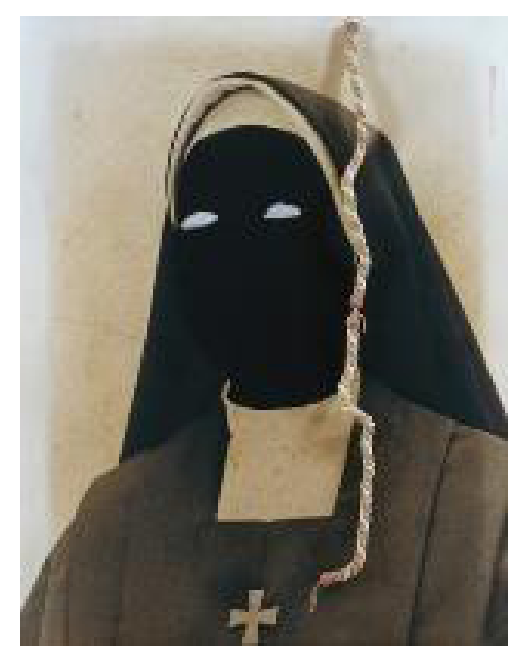

Figura 1. No es lo que parece. Obra de la artista Carmen Calvo. Técnica mixta.

El alumnado de Magisterio no se va a dedicar a la producción artística ni tampoco al comercio con obras de artistas, pero sí que pueden convertir el arte en una herramienta capaz de generar grandes satisfacciones pedagógicas (Hernández-Hernández, 2016). Por eso les animamos a utilizar las posibilidades del arte como argumento educativo, como fuerza capaz de revolucionar la sociedad, como aliento que inspira los cambios y las mejoras sociales. Hemos convertido este taller en un proyecto de innovación educativa titulado «El miedo, geografías del temor», donde abordamos desde el arte este aspecto tan importante para nuestras vidas. El tema no forma parte 
del currículum de formación de maestros, ni tampoco se tata habitualmente en los estudios universitarios de Magisterio, pero consideramos que es un aspecto vital (Foucault, 2009) y por tanto algo que resulta importantísimo tanto para el alumnado como para el profesorado.

El miedo, los miedos, constituyen sensaciones y emociones, estados de ánimo y comportamientos que nos afectan y nos transforman (Antón Hurtado, 2015). Asumir los miedos y elaborar un discurso combativo frente a ellos puede resultar muy gratificante si se convierte en un elemento motivador para nuestras clases (Foucault, 1998). Las mujeres saben muy bien de qué estamos hablando cuando nos referimos al miedo (López Fernández-Cao, 2016). Pero los miedos nos afectan a todos, y por ello conviene conversar abiertamente sobre ello, y al mismo tiempo realizar acciones artísticas de talante colaborativo.

Al inicio de cada propuesta el alumnado no se siente capacitado para elaborar un discurso artístico. No perdamos de vista que se trata de alumnado de grado de Magisterio. La mayoría han tenido poco o nulo contacto anterior con el arte o con la creación artística en general. No son conscientes de sus capacidades, ya que desde siempre les han insistido en que «no eran buenos para el arte». Nos relatan situaciones que vivieron en la escuela y el instituto, escenas y experiencias poco alentadoras que les marcaron negativamente para continuar creando. Es habitual entre nuestro alumnado que opinen usando expresiones como: "Yo no sé dibujar ni hacer arte»; «Mis profesores me decían que era negada para el arte»; «Me veo incapaz de hacer una obra de creación»; «Ese es un campo que no controlo, ya que nunca se me ha dado bien». Cuando iniciamos cada proyecto, les digo que deben repensar sus posibilidades creativas. Han de replantearse qué significa hacer arte, pero sobre todo han de empoderarse de sus propias posibilidades como personas creativas. Las sesiones de reflexión ocupan la primera parte de la preparación del proyecto. Hablamos sobre las necesidades y los intereses del propio alumnado en relación con este tema, y de este modo se establece una relación de confianza que resultará fundamental para continuar con el trabajo.

En el caso de la propuesta «El cuerpo» utilizamos la idea del cuerpo como construcción cultural (Butler, 2002). En las escuelas aprendemos a pensar nuestro cuerpo desde lo fisiológico. Se le habla al alumnado escolar de sus cuerpos como si en realidad no estuviesen allí. La represión de carácter religioso, médico o político ha repercutido en una mirada hacia el propio cuerpo llena de prejuicios y tabúes (Butler, 2006). Es por ello que nos atrevemos a superar las tiranías tradicionales para reivindicar un cuerpo más allá de su función social, rompiendo con las obsesiones por el color de la piel, o por el hecho de ser más altos, bajos, gordos o flacos, feos o guapos, masculinos o femeninos (Winterson, 2012). En la diversidad está la fuente de la riqueza, y el respeto a la diversidad es el primer paso hacia una sociedad más justa y equitativa. Para hablar sobre las proezas de los cuerpos diversos utilizamos como ejemplo la obra de la artista Anna Ruiz Sospedra. Sus esculturas (en muchos casos obras efimeras, especialmente fallas) nos presentan los cuerpos (https://www.flickr. com/photos/anna ruiz) desde una perspectiva abierta y transgresora (Figura 2).

Generamos el taller del cuerpo como un proyecto de innovación educativa que denominamos «Cuentas pendientes con nuestros cuerpos». Abordamos la cuestión desde el arte, hablando de la obra de artistas de todas las épocas y estilos, partiendo de los gustos del alumnado (Lord y Meyer, 2013). El cuerpo es nuestra forma primaria de comunicación con nosotros mismos y con el exterior, nuestra geografía 
elemental. Nos manifestamos desde nuestros cuerpos, y esta reflexión va más allá de aquello para lo que nuestros cuerpos «habían sido pensados» por parte de las estructuras sociales y culturales. Asumir la realidad de nuestro cuerpo, aceptarnos tal y como somos, superar la heteronormatividad imperante (García, 2015) resultará fundamental para poder transmitir, como docentes, una mirada desprejuiciada hacia nuestras fisionomías y sus posibilidades culturales.

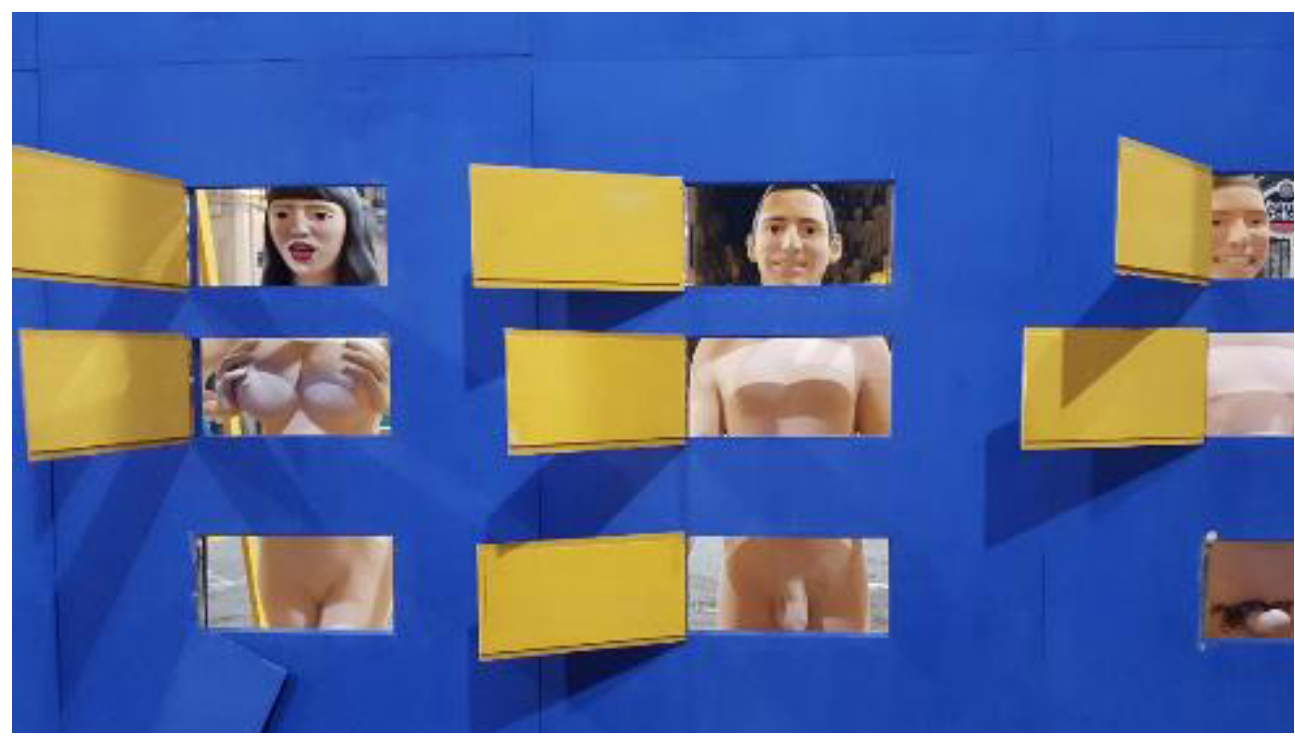

Figura 2. «Falla Lepanto-Guillem de Castro 2017». Obra de Anna Ruiz Sospedra.

Al acercarnos a la visión del cuerpo que transmiten las obras de Anna Ruiz Sospedra, el alumnado de Magisterio puede repensar la imagen del binomio masculino y femenino, eliminando así prejuicios raciales, sociales o religiosos, urdiendo nuevas posibilidades de representación de los cuerpos, más allá del contraste hombre/ mujer entendido como macho/hembra (Planella y Pié, 2015). También estudiamos las formas de representación de los cuerpos que lleva a cabo en sus obras. Incluso invitamos a venir a clase a la artista, que nos habla en persona de sus ideas y de cómo las resuelve y las lleva a cabo de manera artística. Este contacto con una persona reconocida en el mundo del arte resulta importante para el alumnado, ya que pueden dialogar con una creadora reconocida, y es esta conversación la que consigue eliminar ciertos prejuicios que pueden tener respecto a las manifestaciones del arte.

\section{Interpretaciones artísticas del miedo y del cuerpo por parte de las futuras maestras}

En opinión de Juliana Almeida Duarte «el arte contemporáneo tiene como cuestión básica proporcionar una experiencia; las instalaciones y performances lo hacen con claridad y de manera más radical, implicando la participación del cuerpo, del artista y el espectador. El cuerpo implicado nos lleva a reflexionar sobre el conocimiento sensible» (Duarte, 2016, 
p.142). Este planteamiento de la autora brasileña nos ayuda a reconocer en nuestras experiencias de aula un proceso significativo que pretende implicar al máximo al alumnado universitario, en este caso a futuros maestros y maestras. No se trata de especialistas en historia del arte ni tampoco de artistas, sino de maestros que utilizan el arte como estrategia educativa (Huerta, 2015). Planteamos un taller en el que van a reflexionar sobre sus miedos, y al mismo tiempo van a realizar una instalación artística. El trabajo se ejecuta en equipo, por grupos de cinco personas. Cada equipo expone su idea, y durante tres semanas se elabora la propuesta. En clase se habla básicamente de las posibilidades que genera la obra artística de Carmen Calvo (http:/www.carmencalvo.es). También introducimos a otros artistas que han sabido plasmar el miedo en sus creaciones.

En la figura 3 vemos una instalación con la que el alumnado quiere representar los miedos de quienes sufren agresiones por acoso. Tres figuras ahorcadas acompañan los tres testimonios escritos (de casos reales) en los que niños que se han suicidado explican su desesperación ante la violencia de sus compañeros y el acoso que sufrían por bullying homofóbico. Tanto la idea inicial como su desarrollo en el taller provocan un alud de aportaciones que imprimen al trabajo una fuerte carga emotiva. Los muñecos de tela han sido confeccionados por los miembros del grupo.

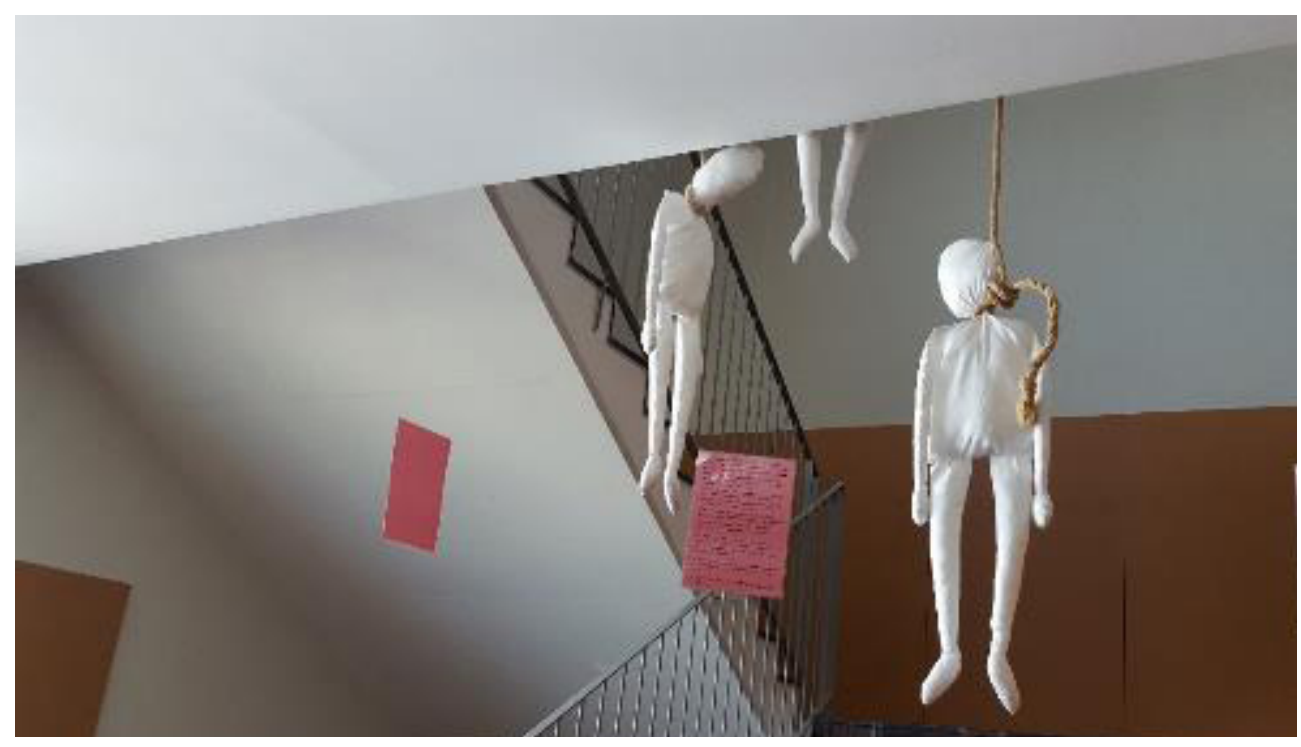

Figura 3. Instalación de alumnos de Magisterio en la que se analiza el miedo a partir del sufrimiento por el bullying, especialmente el acoso homofóbico.

Le preguntamos al alumnado cuáles son sus miedos. Nos contestan que temen: «la soledad», «hablar en público», «perder a un ser querido», «no superar los retos», «no encontrar trabajo cuando terminen los estudios universitarios». En ocasiones temen «decir la verdad por miedo a las represalias». Se entabla un diálogo entre sus ideas y la obra de Carmen Calvo. Esta artista introduce elementos muy cotidianos en sus montajes: muñecas, fragmentos de telas, muebles, ladrillos. El alumnado debe asumir que se puede hacer arte con objetos sencillos. Se trata de encontrar la poética del objeto, transitando por la línea de la poesía visual. A partir de aquí se inicia el 
taller para que cada equipo construya una instalación artística plasmando sus reflexiones sobre los miedos.

Durante las sesiones de realización del taller se asesora al alumnado en aspectos como la selección de materiales, la unión de elementos constructivos, o bien el juego estético de colores y texturas. Al mismo tiempo se van concretando los aspectos conceptuales de cada obra, elaborando un discurso en imágenes que posteriormente se ha de exponer en público (Rolling, 2010). Se les explica que el lugar en el que decidan instalar la pieza puede favorecer una serie de lecturas fecundas, para lo cual se establece un criterio de situación de las piezas en los distintos espacios de la facultad (pasillos, ascensores, escaleras, servicios).

Las lecturas de la obra de Carmen Calvo han de tener en cuenta algunos rasgos que la caracterizan: el fetichismo y su pasión por los objetos fetiche, las poéticas relacionales, las representaciones de la violencia y la sexualidad desde los relatos del poder (roles sexuales y aceptación de la violencia cotidiana), el dolor en la infancia, la lucha por la libertad, el dominio del horror. La artista plasma con sus obras estos desafios, retos que están muy pendientes de las injusticias que todos conocemos y contra las que nos rebelamos. Quienes nos dedicamos a la docencia hemos de aprender a reflexionar sobre estas problemáticas para actuar, y aquí es donde el arte nos ofrece más posibilidades (Fernández de Juan, 2017).

Cuando finalizó el taller y pudimos ver el excelente resultado de los trabajos, nos pusimos de nuevo en contacto con la artista Carmen Calvo, quien aceptó la invitación de venir a visitar la exposición. Se sintió muy emocionada porque le resultaba novedoso que fuesen los futuros maestros quienes trabajasen a partir de sus obras. Este tipo de recreaciones es habitual en los estudios Bellas Artes, pero no en los de Magisterio. En una entrevista para la televisión de la universidad la artista llega a afirmar que «el nivel de los trabajos del alumnado de Magisterio es muy alto, y podría equipararse a las propuestas que se están haciendo en facultades de artes $»^{2}$.

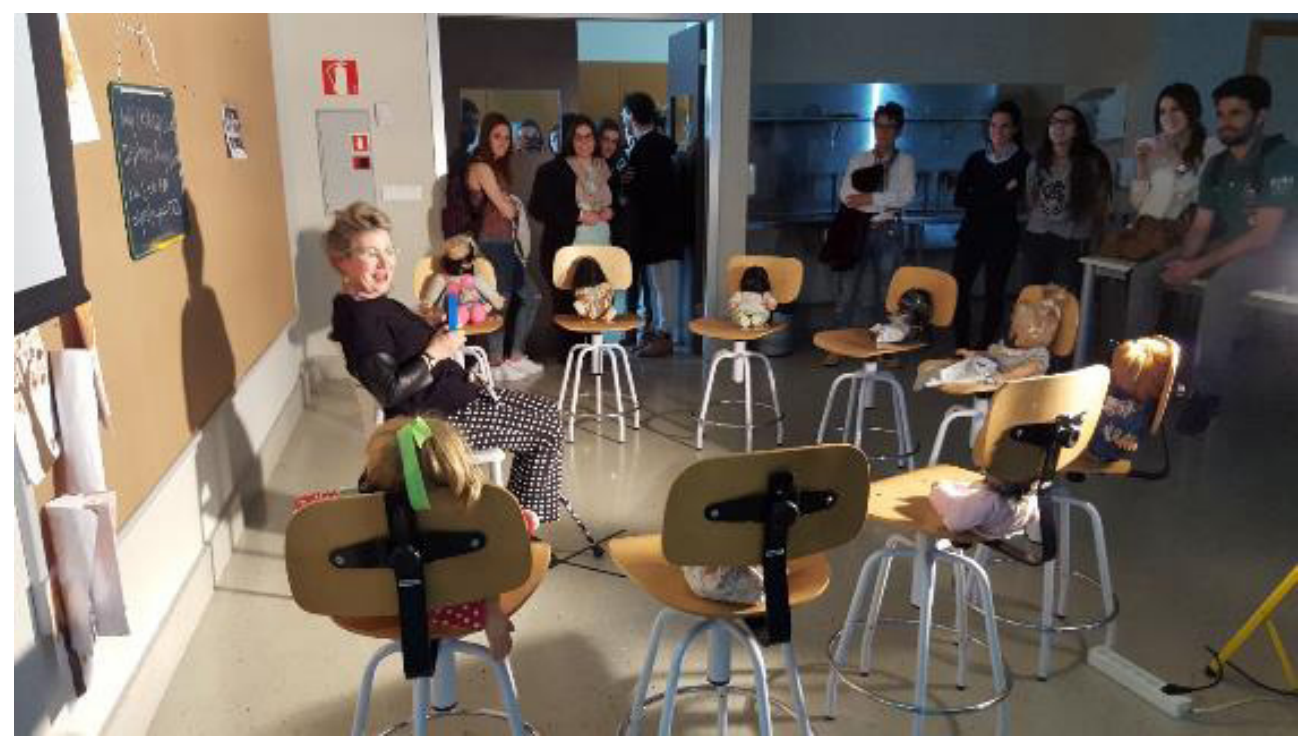

Figura 4. Instalación realizada por alumnado del taller del proyecto sobre el miedo.

2 Para ver la entrevista: http://www.uv.es/uvweb/universidad/es/videos/listado-videos/artista-carmen-calvo-homenatjada-facultat-magisteri-universitat-valencia-1285868042985/Recurs.html?id=1285965527063 
La instalación que representa la figura 4 plantea el miedo a hablar en público. Una serie de muñecas (figura habitual en la obra de Carmen Calvo) observan al personaje que se ubica en el interior del montaje. En este caso es la propia artista Carmen Calvo quien interactúa con la obra de los alumnos. Un círculo de muñecas intervenidas sentadas sobre taburetes miran hacia el centro, donde se sitúa el visitante. Al mismo tiempo las figuras sentadas la observan, algo imposible puesto que llevan las caras cubiertas con objetos que les impiden ver. La sensación que se crea es asfixiante, y realmente produce «miedo». En esta instalación se hace referencia al miedo de los más pequeños cuando se les pide hablar en público. Las alumnas que han realizado el montaje querían implicar al máximo al visitante, al usuario, incitándole a participar activamente.

El uso de objetos dentro del lenguaje artístico nos lleva hacia una poética de lo objetual. Este es un mensaje que siempre resulta atractivo para el alumnado. La poética está presente en la mirada que lanzamos hacia los objetos, algo que después se explica a través del lenguaje, tanto verbal como icónico (Pallarès y Traver, 2017). Un buen ejemplo de ello es la obra de Giorgio Morandi. John Berger lo explica del siguiente modo: «los objetos que pintó Morandi no se pueden comprar en un mercado callejero. No son objetos. Son lugares (todo tiene su lugar), lugares en donde nacen pequeñas cosas» (Berger, 2004, p.153). Visto de este modo, los objetos adquieren un carácter conceptual que los convierte en manifestaciones de sentido. Así pues, los objetos representados por Morandi ya no son la pieza en sí, se han convertido en una poética de la relación de dicho objeto con todo aquello que le rodea.

Con el proyecto «El cuerpo» analizamos en clase las formas con que se trata este tema a nivel curricular en las escuelas. Nos damos cuenta de que las miradas hacia el cuerpo por parte del entorno formal están llenas de prejuicios.

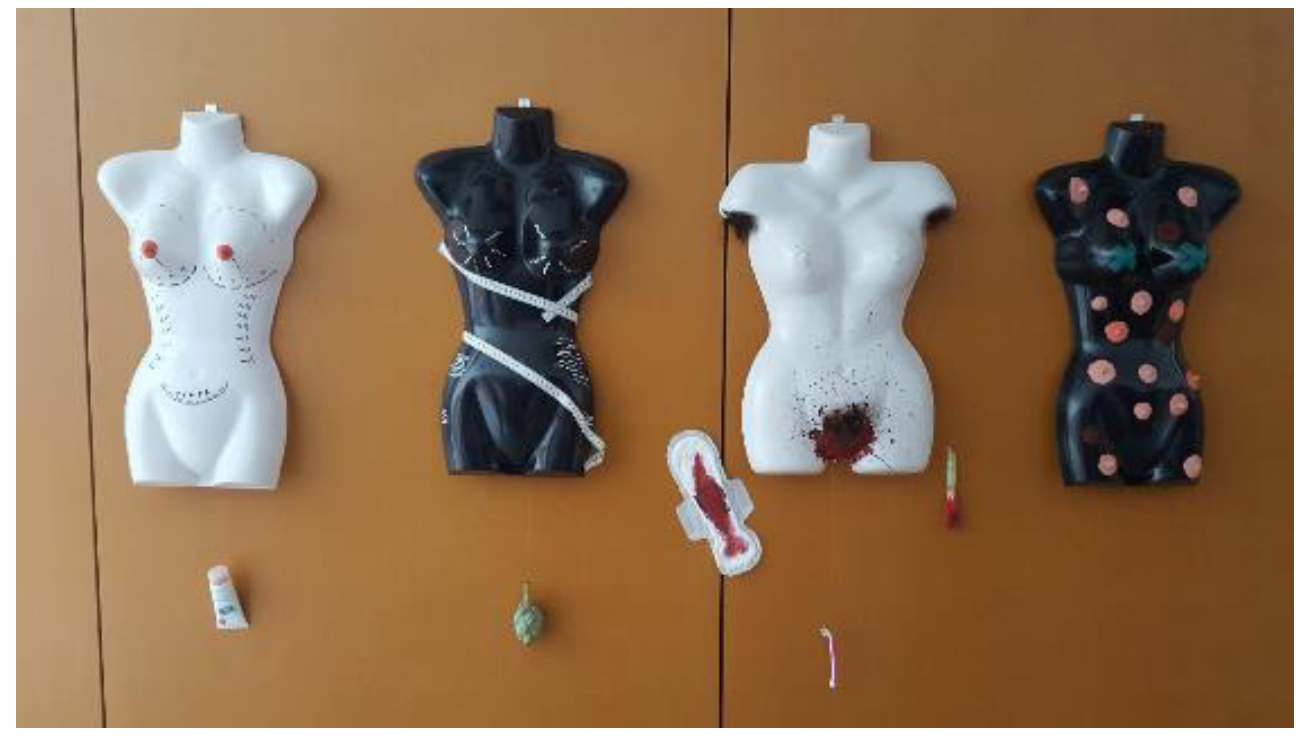

Figura 5. Instalación de un grupo de alumnas de Magisterio en la que se denuncian las presiones que se ejercen sobre el cuerpo femenino. 
Las instalaciones que realiza el alumnado de Magisterio utilizan elementos de reciclaje y objetos cotidianos. En la figura 5 aparecen cuatro maniquís que representan cuatro formas de presión sobre el cuerpo de la mujer: 1) la obcecación por un cuerpo «de dimensiones perfectas», lo cual lleva a obsesionarse por las medidas y el peso. 2) Las dietas agresivas. 3) El empeño por ocultar los pelos (axilas) o la sangre (regla) como si se tratase de cosas «feas o sucias». 4) La obstinación de las redes sociales por prohibir la imagen de los pezones en los pechos de la mujer (no ocurre lo mismo en el caso de los hombres). El uso del cuerpo como representación de lo humano sigue preocupando al alumnado de Magisterio, ya que el cuerpo constituye el concepto cultural más sofisticado y debatido, especialmente cuando pensamos en los niños y las niñas, quienes serán sus alumnos en el futuro. Por ello consideramos de máximo interés y urgencia que los futuros maestros analicen el cuerpo como una construcción cultural. Así lo remarca Jordi Planella cuando afirma que en el momento en que los sujetos son educados para saberse inseridos históricamente, tiene sentido «hablar de la historia del cuerpo y de su narratividad. Pero hablar de la condición de historicidad del cuerpo exige hacer referencia a la misma condición de narratividad de los cuerpos. Los cuerpos, ¿se pueden narrar?» (Planella, 2006, p.52).

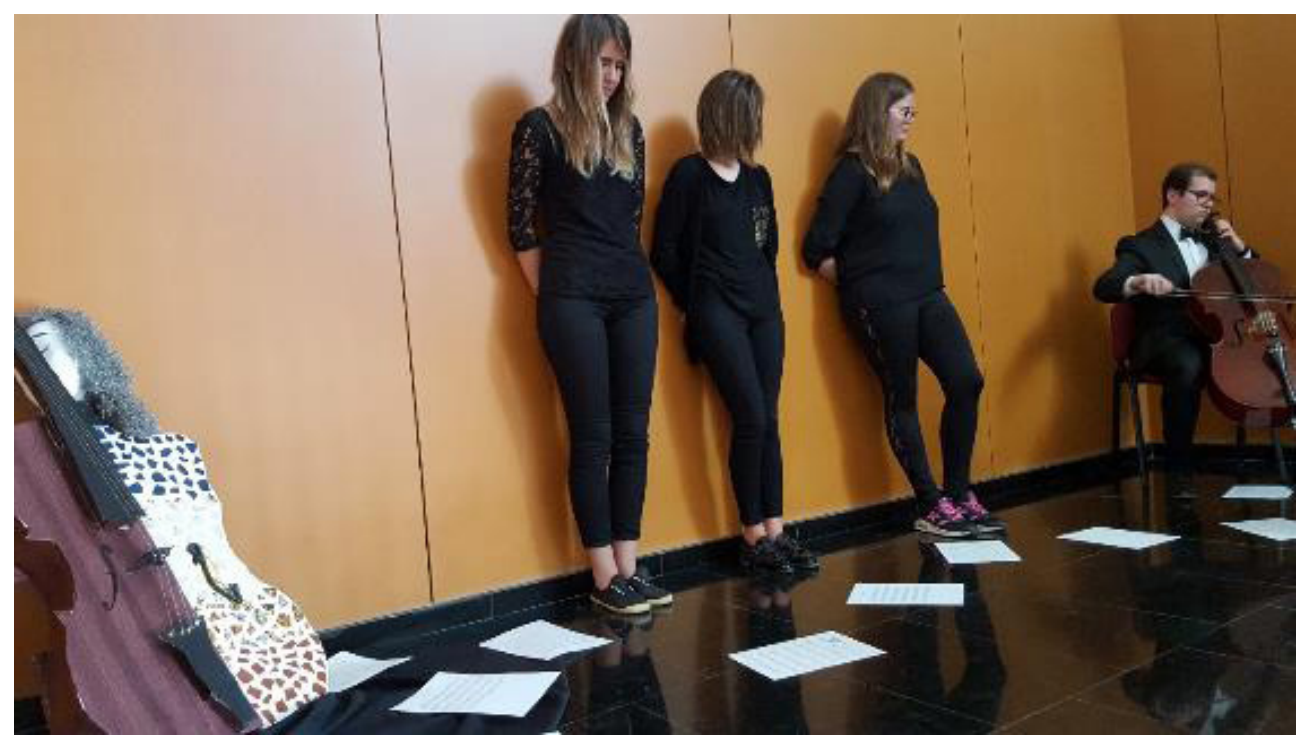

Figura 6. Performance del alumnado en la que se transmiten los abusos hacia el cuerpo mediante música y teatralización.

Esculturas, instalaciones y acciones performativas servirán para transmitir una nueva mirada hacia el cuerpo. La imagen de la figura 6 representa un performance en el que se plantea el uso del cuerpo de la mujer como modelo artístico, revisando la famosa figura de la «musa» en tanto que modelo pintada por artistas hombres. Los futuros docentes han narrado sus visiones del cuerpo desde la perspectiva del arte. Las instalaciones realizadas nos hablan de expectativas, de intereses, de deseos, de saberes, todo ello desde las poéticas de la expresividad. Han trabajado en equipo y por tanto han sido capaces de colaborar para realizar 
una pieza artística. El espíritu de cooperación ha estado presente en toda la evolución del proyecto, ya que se han aportado ideas, se han contrastado opiniones, y finalmente se han tomado decisiones conjuntas. Este modo de trabajar en el taller de arte es el que deseamos fomentar, un modelo colaborativo que permite estimular el consenso y que acentúa las posibilidades expresivas y comunicativas de los futuros y las futuras docentes. Al mismo tiempo hacemos uso de las instalaciones ubicándolas en espacios comunes de la facultad para que todas las personas que transiten puedan disfrutar de los trabajos del alumnado, expuestos en sitios curiosos y peculiares.

\section{Mostrar las producciones del alumnado en los espacios de tránsito de la facultad}

El hecho de saber que sus producciones serán expuestas en los espacios de la facultad constituye un factor añadido de motivación para el alumnado. Durante la fase de realización del proyecto, la idea de poder enseñar públicamente sus instalaciones incide positivamente en el interés por ser innovadores y atrevidos (Marañón, 2018). Por otro lado, al utilizar los espacios del centro como entorno expositivo, convertimos la facultad en un pequeño museo de piezas realizadas por el alumnado, que se exponen en los lugares más insospechados. Convertimos el edificio en un laboratorio de ideas, un pequeño museo experimental, una reivindicación de la curaduría educativa (Rogoff, 2008). Recordamos las palabras de Chiara Panciroli cuando se refiere al museo como entorno privilegiado para la educación, ya que con estos montajes provocamos «Un proceso de recreación poética, un esfuerzo de imaginación combinado con un riguroso conocimiento» (lo cual) «representa uno de los posibles modos de interpretar la realidad» (Panciroli, 2016, p. 87)

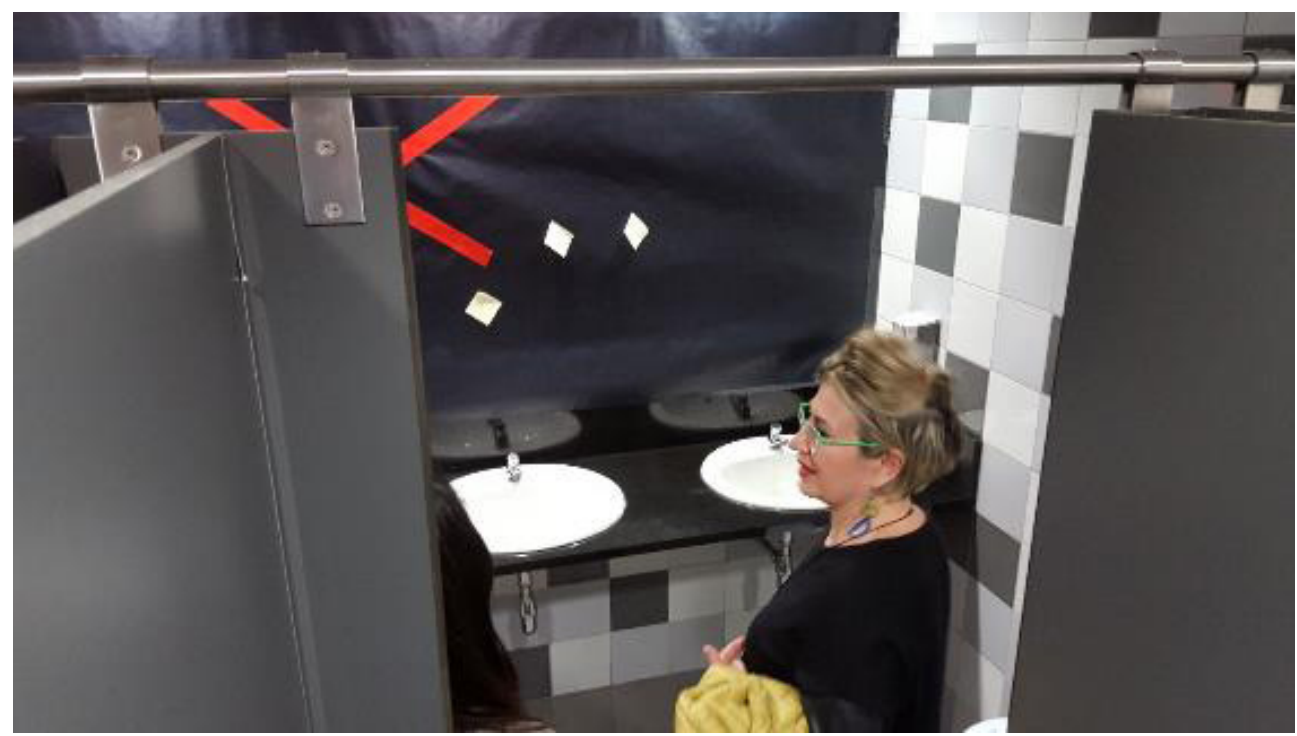

Figura 7. La artista Carmen Calvo observa la instalación creada por el alumnado en unos servicios de la facultad. 
En la foto de la figura 7 vemos una instalación del proyecto «El miedo» montada en los servicios de la última planta del edificio de la facultad. La intervención consiste en tapar el espejo del servicio con un plástico negro. Al eliminar el reflejo y no poder vernos en él, la sensación es muy extraña. Desaparece nuestra imagen, desparecemos nosotros en tanto que personajes que reverberan en la reproducción del espejo. El efecto de soledad es sorprendente. Éste era uno de los miedos a los que hacían referencia el alumnado: el miedo a la soledad.

«El miedo» y «El cuerpo» son en realidad temáticas tabú en el currículum escolar. Por ello tampoco se tratan como temas habituales en la formación de maestros. Al plantearles estos temas desde el arte y la educación artística generamos un estímulo eficaz entre el alumnado, que se siente implicado desde el inicio de cada proyecto. Durante el proceso de realización de las instalaciones surgen dudas, preguntas, sugerencias, cambios, para finalmente lograr resultados muy interesantes, que hablan de aspectos muy humanos a través de las poéticas de las artes.

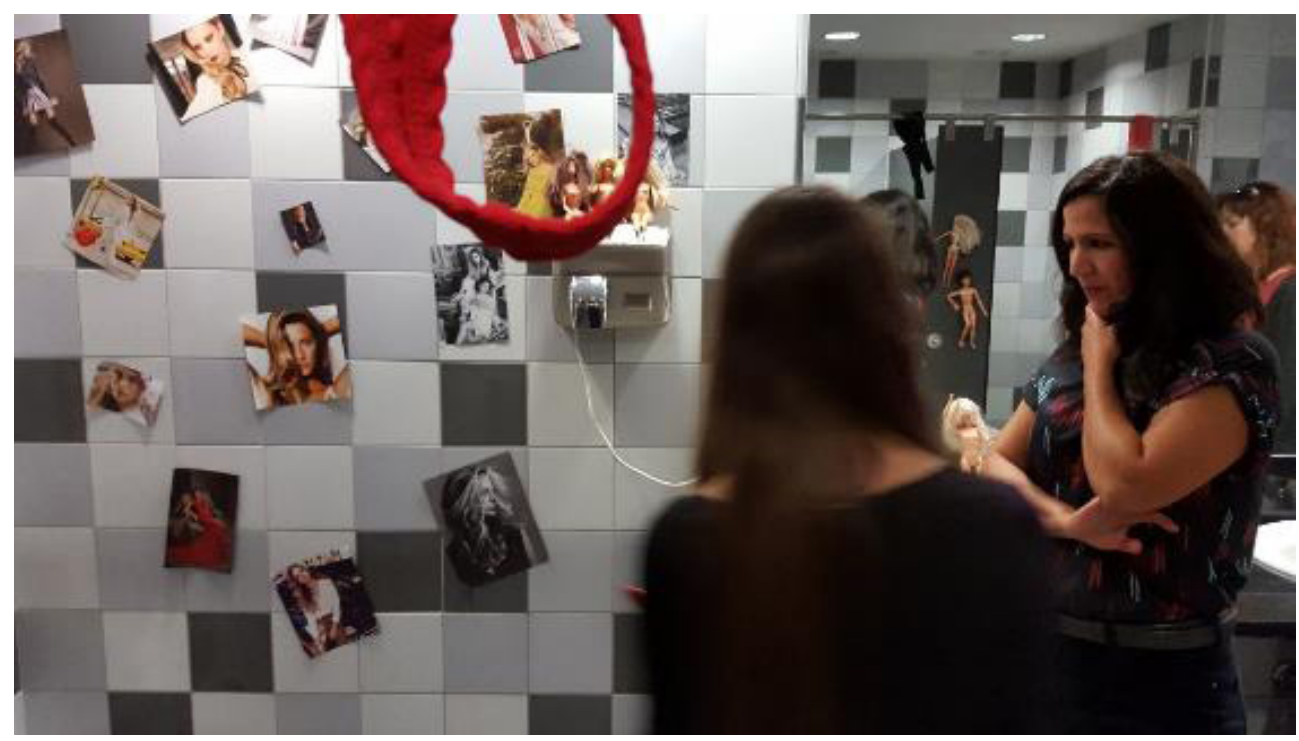

Figura 8. Una alumna explica a la artista Anna Ruiz Sospedra su instalación sobre «El cuerpo» creada con fotografías y objetos en los servicios de la facultad.

La ocupación del espacio por parte del alumnado a través de sus instalaciones supone un reto de organización, especialmente cuando se trata de lugares de paso y uso común. Al preparar las acciones hay que pedir permiso a la dirección del centro, comprometiéndose a no estropear ninguna instalación, y a dejar posteriormente en perfectas condiciones los entornos utilizados. Este esfuerzo de coordinación supone al mismo tiempo un buen modo de transmitir el respeto hacia los espacios públicos. El efecto sorpresa surge cuando el resto del alumnado comprueba que han sido intervenidos lugares «poco habituales para exposiciones de arte» como puedan ser pasillos, servicios, escaleras o incluso ascensores (Figura 9). Con estas acciones se reivindica un mayor aprovechamiento de los equipamientos, convirtiendo así un pasillo o el aula en entornos artísticos de exhibición. 


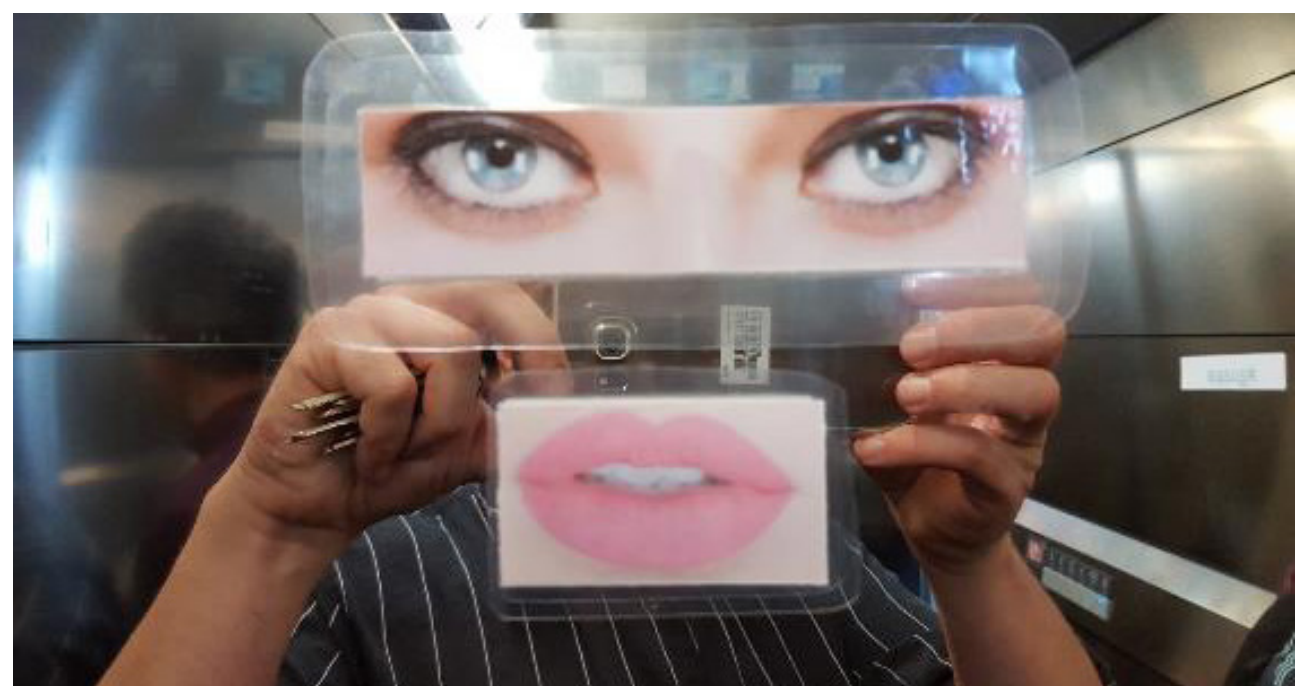

Figura 9. Intervención artística sobre «El cuerpo» en un ascensor de la facultad.

El efecto sorpresa es una de las características que mantiene el interés por descubrir alicientes que provocan las instalaciones en lugares estratégicos. El ascensor es un lugar de paso, un espacio pequeño y asfixiante. El espejo del ascensor permite aparentemente ampliar el espacio observado de una pequeña cabina, pero también puede convertirse en un elemento de reflexión si nos «empoderamos» de dicho espacio para animar a quien lo utiliza a pensar en su propio cuerpo como moneda de cambio (Figura 10). Lo que conseguimos con estos «site specific» es generar interés por el arte tanto entre el alumnado que genera las piezas como en resto de usuarios de la universidad. La utilización de los espacios es un elemento propio de las «artografías» (Irwin y O’Donoghue, 2012).

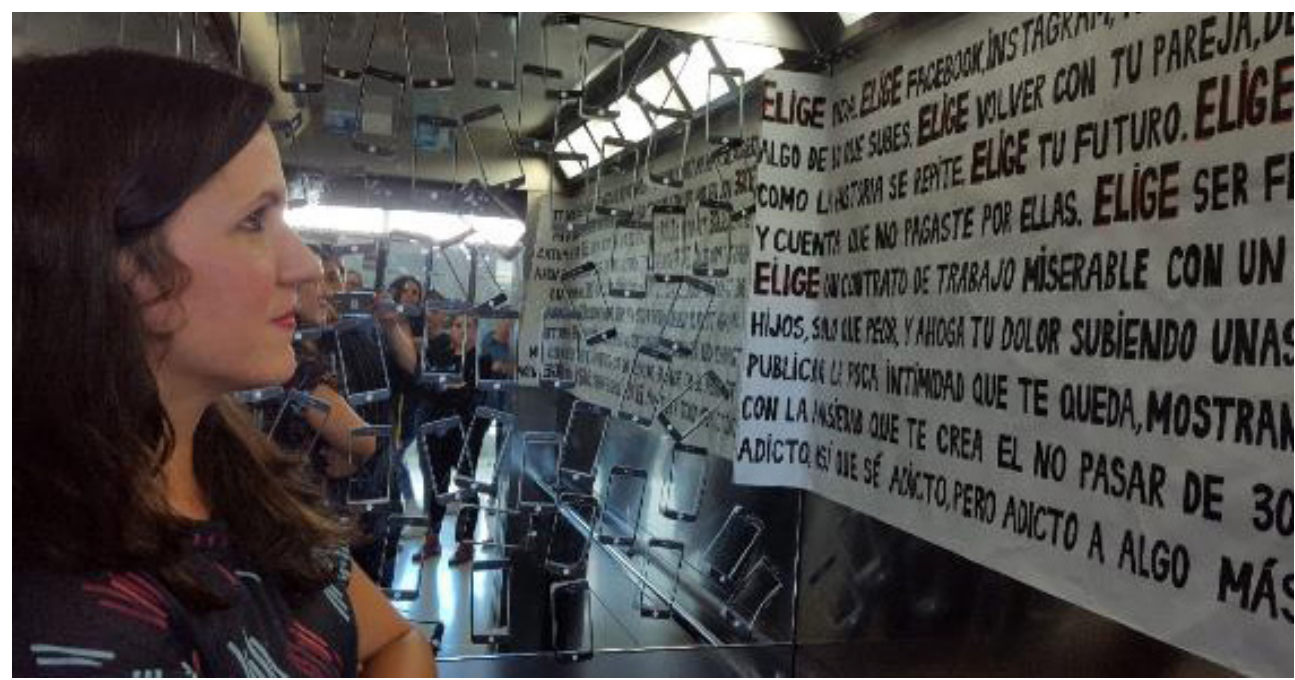

Figura 10. La artista Anna Ruiz Sospedra observa una intervención artística sobre el tema «El cuerpo» en un ascensor de la facultad. 
Uno de los aspectos que quisimos potenciar en ambos proyectos («El miedo»y «El cuerpo») fue la lucha contra el acoso escolar. A los niños que padecen acoso hay que ayudarles, y para ello debemos tomar conciencia de la gravedad de la situación. La importancia del bullying (acoso escolar) es tan evidente que no podemos narrarlo mediante representaciones superficiales. Hay que adentrarse en estas problemáticas con valentía (Pichardo, 2015). De este modo los futuros maestros se enfrentan a una problemática enquistada mediante instalaciones artísticas en las que plasman sus deseos de mejorar la situación.

\section{Conclusiones}

Tras haber realizado los proyectos «El miedo» $\mathrm{y}$ «El cuerpo» con alumnado de Magisterio, comprobamos el buen nivel del trabajo artístico llevado a cabo por las futuras maestras. Mediante instalaciones artísticas reflejan sus temores analizando sus miedos y sus cuerpos, generado significados con el uso de objetos cotidianos y de espacios públicos. Se han empoderado de la mirada intensa del arte, y han sabido concretar sus ideas mediante poéticas visuales. Cuando iniciamos la asignatura de Proyectos nos confiesan que no confían de sus posibilidades artísticas, ni tampoco reconocen sus potenciales creativos. De hecho desconfían de poder llegar a buenos resultados en el terreno creativo. A la mayoría siempre les habían dicho que «no eran buenas» para la creación artística. Al terminar sus trabajos comprueban que eran capaces de transmitir sus ideas mediante las artes, a través de instalaciones, fotografías, videos, dibujos e intervenciones performativas. Ahora se han empoderado del uso de las artes, y ya son conscientes de sus posibilidades, habiendo superado los miedos iniciales. De eso se trataba, de superar los miedos y de reflexionar sobre las representaciones y los usos culturales del cuerpo.

Cada año, con cada nuevo grupo de clase, recuperamos la confianza en el trabajo docente y en la capacidad del alumnado para enfrentarse al lenguaje artístico. De este modo, cada curso volvemos a superar los miedos iniciales, del mismo modo que el alumnado se enfrenta a los prejuicios que tenía sobre el potencial educativo de las poéticas del arte. Con estos proyectos se consigue transitar por una serie de etapas de preparación y ejecución, al tiempo que se elaboran ideas y se realizan instalaciones artísticas. Todo ello contando con la participación de artistas actuales, como es el caso de Carmen Calvo y Anna Ruiz Sospedra, dos mujeres profesionales del arte que han animado muchísimo al alumnado, especialmente cuando vienen al aula para hablar con el grupo de clase, o bien después cuando visitan las exposiciones de sus trabajos. Resulta fundamental contar con el apoyo de artistas para llevar adelante un planteamiento de educación artística basado en las emociones y en las buenas prácticas.

\section{Referencias}

Antón Hurtado, F. (2015). Antropología del miedo, en Methaodos. Revista de ciencias sociales, 3 (2), 262-275.

Balló, J. (2000). Imatges del silenci. Els motius visuals al cinema. Barcelona: Empúries.

Berger, J. (2004). El tamaño de una bolsa. Madrid: Taurus. 
Butler, J. (2002). Cuerpos que importan: Sobre los límites materiales y discursivos del «sexo». Buenos Aires: Paidós.

Butler, J. (2006). Deshacer el género. Barcelona: Paidós.

Duarte, J. (2016). Saber sensível para a educação: como a mediação cultural em Arte Contemporânea pode atuar na sala de aula, en Revista Matéria-Prima, 4 (3), 139-146.

Fernández de Juan, T. (2017). El arte que cura: Aplicación de técnicas vs la violencia. Experiencias en Baja California, México, en Arteterapia. Papeles de arteterapia y educación para inclusión social, 12, 95-107.

Foucault, M. (1998). Historia de la sexualidad II: el uso de los placeres. México: Siglo XXI.

Foucault, M. (2009). Vigilar y castigar: nacimiento de la prisión. México: Siglo XXI.

Freire, P. (2015). Pedagogia da autonomia: saberes necessários à prática educativa. Rio de Janeiro: Paz e Terra.

García, U. A. (2015). Un marco teórico inclusivo. Teoría de los marcos de género, en EARI Educación Artística Revista de Investigación, 6, 84-98.

Hernández-Hernández, F. (2000). Los proyectos de trabajo. Mapa para navegantes en mares de incertidumbre. Cuadernos de Pedagogía, 310, 78-82.

Hernández-Hernández, F. (2016). Teaching the unknown to facilitate the emergence of a pedagogical event. Visual Inquiry: Learning \& Teaching Art, 5 (1), 87-95. DOI: 10.1386/ vi.5.1.87_1

Huerta, R. (2012). Mujeres maestras. Identidades docentes en Iberoamérica. Barcelona: Graó.

Huerta, R. (2014). La educación artística como motor de cambio social. Cuadernos de Pedagogía, 449, 46-50.

Huerta, R. (2015). La ciudad y sus docentes. Miradas desde el arte y la educación. Barcelona: UOC.

Huerta, R. y Alonso-Sanz, A. (eds.) (2017). Entornos informales para educar en artes. Valencia: PUV.

Irwin, R. y O'Donoghue, D. (2012). Encountering pedagogy through relational art practices, en International Journal of Art \& Design Education, 31 (3), 221-236.

Laddaga, R. (2006). Estética de la emergencia. Buenos Aires: Adriana Hidalgo.

López Fernández-Cao, M. (2016). Curar las heridas: La creación para evocar la ausencia. La memoria de la escritura. La memoria del cuerpo, en Arteterapia. Papeles de arteterapia y educación para la inclusión social, 11, 365-384.

Lord, C. y Meyer, R. (2013). Art \& Queer Culture. Londres: Phaidon.

Marañón Martínez de la Puente, R. (2018). Enocultura e identidad: La instalación como nuevo método de investigación artística en Educación Patrimonial, en Athenea Digital, 18(1), 431-450. https://doi.org/10.5565/rev/athenea.1854

Martins, M. C., Demarchi, R. (2016). Educação como matéria-prima' e mediação cultural: 'entreS' experiências, en Revista Matéria-Prima, 4 (3), 128-138.

Pallarès, M. y Traver, J. A. (2017). Sobre las interpretaciones pedagógicas de Habermas y Rorty: Más allá del modelo fundacionalista, en Athenea Digital, 17 (2), 289-311.

Panciroli, Ch. (2016). Los bienes culturales como patrimonio educativo, en EARI Educación Artística Revista de Investigación, 7, 86-99.

Pichardo, J. I. (2015). Abrazar la diversidad: propuestas para una educación libre de acoso homofóbico y transfóbico. Madrid: Instituto de la Mujer.

Planella, J. (2006). Cuerpo, cultura y educación. Bilbao: Desclée de Brouwer.

Planella, J. y Pié, A., -coords.-(2015). Políticas, prácticas y pedagogías TRANS. Barcelona: Editorial UOC. 
Rogoff, I. (2008). Turning, en e-flux Journal, \#00, 32-46.

Rolling,J.H.(2010).AparadigmAnalysisofArts-BasedResearchandImplicationsforEducation. Studies in Art Education, 51 (2), 102-114. DOI: 10.1080/00393541.2010.11518795

Winterson, J. (2012). ¿Por qué ser feliz cuando puedes ser normal? Barcelona: Lumen.

Zafra, R. (2017). El entusiasmo. Precariedad y trabajo creativo en la era digital. Barcelona: Anagrama. 